RESEARCH REPORT

\title{
Exploring the relation between class, gender, and self rated general health using the new socioeconomic classification. A study using data from the 2001 census
}

\author{
Frances Drever, Tim Doran, Margaret Whitehead
}

J Epidemiol Community Health 2004;58:590-596. doi: 10.1136/jech.2003.013383

See end of article for authors' affiliations

.....................

Correspondence to:

Dr T Doran, Department of Public Health, University of Liverpool, Whelan

Building, Quadrangle,

Liverpool L69 3GB, UK;

timdoran@liverpool.ac.uk

Accepted for publication

21 October 2003 elation between class, gender, and self rated health in adults in Great Britain.

Objective: To examine the relation between class, gender, and self rated
Design: Cross sectional study using data from the 2001 national census.

Setting: Great Britain.

Participants: Adults aged between 25 and 64 in Great Britain, enumerated in the 2001 census ( $n=30.3$ million).

Main outcome measures: Age standardised rates of self rated general health for men and women in different socioeconomic groupings as defined by the National Statistics classification (NS-SeC), rate ratios and the (modified) relative index of inequality.

Results: There was a pronounced gradient in rates of "not good" health among people in different social positions. The rate for people in class 7 (routine occupations) was more than double that for people in class 1 (higher managerial and professional occupations): 95 per 1000 and 37 per 1000 respectively. Health inequalities were larger for men than for women - the rate ratio of class 7 to class 1 was 2.7 for men and 2.2 for women. The nature and size of the gender differences varied by socioeconomic class, with the greatest gap among people in class 1 (higher managerial and professional occupations), where the rate for women was $25 \%$ higher than for men.

Conclusions: The NS-SeC shows a pronounced gradient in self rated general health across the population of working age in Great Britain in 2001. It was found that the NS-SeC was a useful measure for women, although it may be better at classifying men. The size of the gender gap in "not good" health varied by NS-SeC class.
$\mathrm{T}$ here are recurring debates in the health inequalities literature concerning the best approach to capture social position in society, and in particular how to be more sensitive to measuring the situation of women. ${ }^{1-5}$ In health related studies in the UK, the most commonly used measures of social position have been the registrar general's Social Class and the Socio-economic Group classifications, both based on occupation. ${ }^{6}$ These classifications have been more frequently used to study inequalities in men than in women, mainly because of the difficulty of classifying women. ${ }^{7}$ Studies that have included both sexes have found that health inequalities are less pronounced across the socioeconomic groups for women than for men, ${ }^{3}$ although this is influenced by whether household or individual based measures of social position are used.

The two registrar general's classifications have been criticised for not being theoretically based or validated. ${ }^{8}$ In response to such criticisms, the Office for National Statistics commissioned the Economic and Social Research Council (ESRC) to undertake a review of government social classifications. This resulted in the development of a new measure of social position, the NS-SeC, to replace the existing classifications in official data collection..$^{9-11}$ The aim was to base the new measure on well grounded sociological theory and to subject it to a rigorous validation process.

Conceptually, the NS-SeC acknowledges the central role that employment relations and conditions play in structuring modern societies. It aims to distinguish between different social positions in terms of both their typical labour market and work situations. Labour market situation covers the source of income, job security, and prospects for economic advancement. Work situation takes into account the degree of control over work and autonomy, as well as the level of responsibility for supervision of others that the job entails. ${ }^{11}$ The NS-SeC is designed to improve the possibility of explaining associations with important outcomes, such as health and education.

The interim version of the classification has been used to explore relations with health in analyses of sample surveys and the ONS longitudinal study. ${ }^{42-14}$ However, an opportunity to study health inequalities among men and women over the whole population arose with the 2001 UK census. This used the final version of the new classification and included a question on self rated general health for the first time. Poor self rated health has been found to be a powerful predictor of subsequent mortality ${ }^{15}{ }^{16}$-it seems that people are excellent judges of their own underlying state of health and future prospects. It therefore provides a relatively simple outcome measure for use in large scale population studies.

The aim of this study was to explore the relation between class, as measured by NS-SeC, gender, and self rated health in adults in Great Britain enumerated in the 2001 national census.

\section{METHODS}

The national census in Britain is usually undertaken every 10 years. It covers many aspects of life for the people living in Britain and is compulsory for all residents to complete. The latest census was undertaken in April 2001.

The second release of data from the 2001 population census in May 2003 included tables of self rated health and class. Data for England and Wales were obtained from the CD ROM supplement to the National Report for England and Wales. ${ }^{17}$ For Scotland, data were downloaded from the 
GRO-Scotland web site. ${ }^{18}$ The relation between class as measured by the NS-SeC, gender, and self rated health was then examined.

\section{Measurement of social position}

Social position was measured by the final version of the NS$\mathrm{SeC}^{11}$ the conceptual basis for which is outlined above. The census allocated people to a class based on their own employment relations in their current employment, or in their last occupation if they were not presently working but had been employed within the previous two years. We used the recommended analytic version of the NS-SeC, which categorises social positions into seven analytic classes (see table 1). The key questions asked in the census that establish which class a person belong to are: occupation; details of employment status (whether employer, self employed, or employee); whether a supervisor or manager and number of employees in the workplace.

Table 1 gives examples of occupations within the categories in the NS-SeC. The examples indicate the breadth of types of occupations within each class. The occupations mentioned in the table are only indicative of the range of the group, rather than of occupations that would always be classified in this way. Wherever possible, occupations have been given that fall completely within one class, regardless of the description of employment status. The employment status may move an occupation to a different class. For example, bakers are given as an example of class 5 (lower supervisory and technical occupations). If a person describes their occupation as "baker" and then says they are the employer of a large number of people, they would be placed in class 1 (large employers and higher managerial and professional occupations). If they were employers of a few people, or self employed with no employees, they would be in class 4 (small employers and own account workers). Full details of which occupations are in which classes is given in table $\mathrm{B} 2$ of the user manual for the NS-SeC. ${ }^{11}$ The category that is most problematic for the purpose of listing examples is class 4 (small employers and own account workers). As with bakers mentioned above, many people may end up in this class depending on their employment conditions. The census used the full information on both job title and employment status to code individuals to a class.

Figures 1 and 2 show the proportions of men and women in each age group classified by the NS-SeC. For men aged 25 to 64 , the proportions classifiable to one of the main employment classes ( 1 to 7 ) ranges from $74 \%$ to $93 \%$. For women aged between 25 and 64, the proportions were smaller, but were still between $57 \%$ and $85 \%$. At the youngest age groups, there were large proportions of full time students: $59 \%$ of men aged 16 to 19 and $64 \%$ of women. We considered that many of those aged 20 to 24 would still be in the process of training or qualifying and not yet have reached their final class and so omitted these ages from the analyses. Those aged over 65 had to be in employment to be included in the classification. This is clearly indicated by the large proportion in the group "not classifiable for other reasons". The cut off age of 65 was used in the census data both for men and for women, although at present the retiral age for women is 60 . Figure 2 shows that nearly $40 \%$ of women aged 60 to 65 were not classified to a social class. We decided to have 65 as our upper age limit, both for men and for women, because the same cut off age was used in the census for both sexes, and to have the same age ranges to enable discussions about differences between men and women. Moreover, well over half of women in this age range were allocated to a class. Thus, we restricted the analyses to those aged 25 to 64 .

We restricted the study to people classified in one of the seven major classes and excluded the rest. The "long termed unemployed" as a group (unemployed for two years or more and allocated to class 8 by ONS) was excluded as it is not recognised as a "class" in any sociological sense: becoming unemployed is a different process to that which decides on class location. Those who had never worked were also excluded, as this group is an amalgam of those who have private incomes as well as those who may be unfit for work through ill health. The groups who were not classified because of not working in the previous five years or for other reasons were also omitted as no conclusions as a whole could be drawn, given the lack of information about them. Thus the final analysis included 26.0 million of the original 30.3 million people enumerated in these age groups (that is, over $86 \%$ of the individuals in this age range).

\section{Measurement of health and analysis}

Respondents to the census were asked to rate their general health over the previous 12 months in one of three categories: "good", "fairly good", or "not good". Age standardised rates for the "not good" health category were calculated by the direct method using the World Health Organisation's European Standard Population. ${ }^{19}$ Separate rates for men and for women aged 25 to 64, in each of the seven main

Table 1 NS-SeC classes and example occupations

\begin{tabular}{|c|c|c|}
\hline & NS-SeC class & Example occupations \\
\hline 1 & $\begin{array}{l}\text { Large employers and higher } \\
\text { managerial and professional } \\
\text { occupations }\end{array}$ & $\begin{array}{l}\text { Directors of major organisations; officers in armed forces; senior } \\
\text { officers in national government; clergy; medical practitioners; higher } \\
\text { education teaching professionals }\end{array}$ \\
\hline 2 & $\begin{array}{l}\text { Lower managerial and professional } \\
\text { occupations }\end{array}$ & $\begin{array}{l}\text { Journalists, newspaper editors; musicians; nurses; paramedics; school } \\
\text { teachers }\end{array}$ \\
\hline 3 & Intermediate occupations & $\begin{array}{l}\text { Graphic designers; medical secretaries; travel agents; ambulance staff } \\
\text { (excluding paramedics); police officers (sergeant and below) }\end{array}$ \\
\hline 4 & $\begin{array}{l}\text { Small employers and own account } \\
\text { workers }\end{array}$ & Farmers; hotel managers; product designers; roofers; taxi-cab drivers \\
\hline 5 & $\begin{array}{l}\text { Lower supervisory and technical } \\
\text { occupations }\end{array}$ & $\begin{array}{l}\text { Bakers; electricians; gardeners; road construction operatives; train } \\
\text { drivers }\end{array}$ \\
\hline 6 & Semi-routine occupations & $\begin{array}{l}\text { Dental nurses; farm workers; housekeepers; scaffolders; traffic } \\
\text { wardens }\end{array}$ \\
\hline 7 & Routine occupations & $\begin{array}{l}\text { Butchers; cleaners, domestics; furniture makers; labourers in building } \\
\text { and woodworking trades; waiters, waitresses }\end{array}$ \\
\hline 8 & $\begin{array}{l}\text { Never worked and long term } \\
\text { unemployed } \\
\text { Full time students; occupations not } \\
\text { stated or inadequately described; not } \\
\text { classifiable for other reasons }\end{array}$ & \\
\hline
\end{tabular}




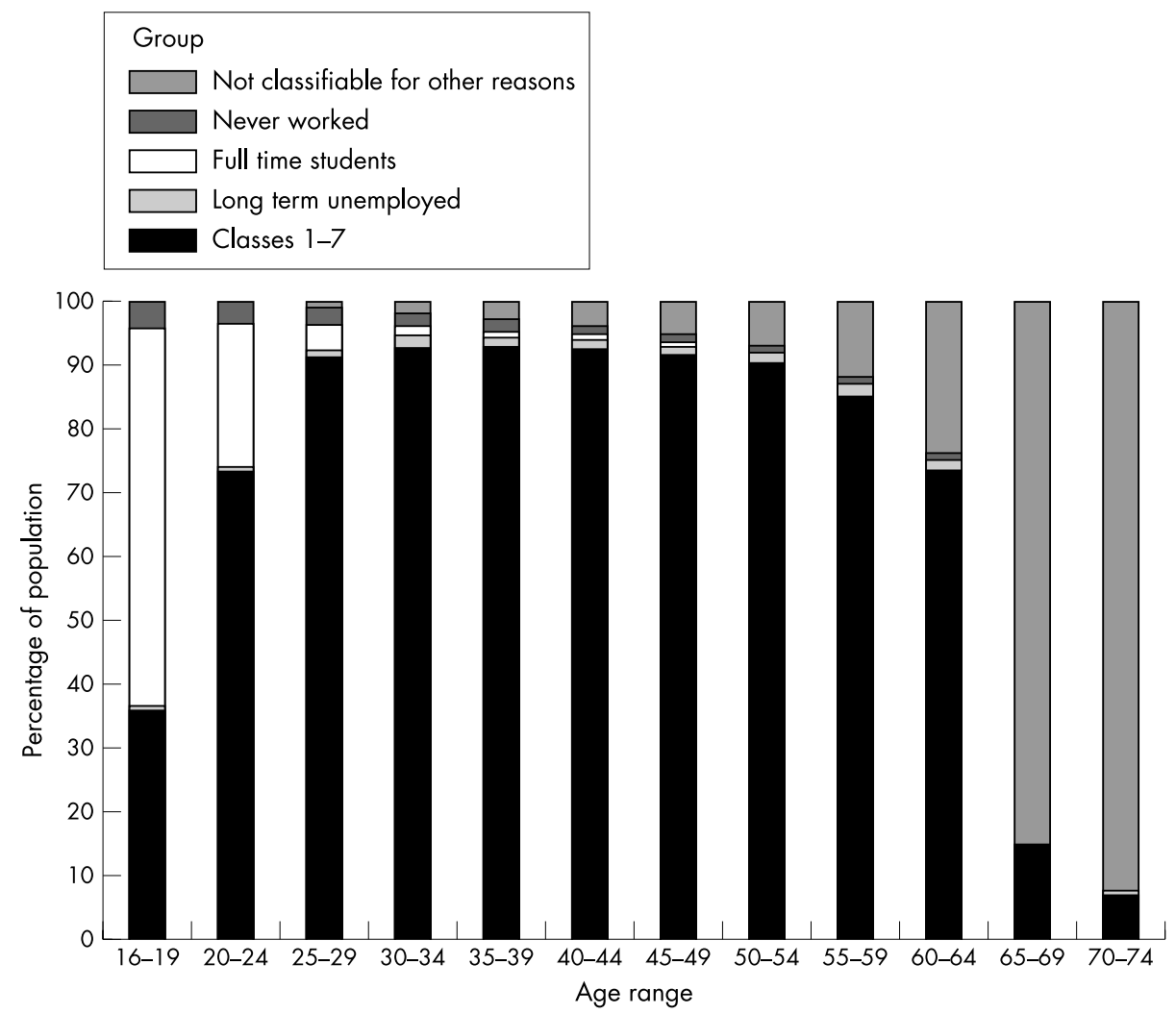

Figure 1 Classification of men aged 16-74 by NS-SeC, Great Britain 2001.

categories of NS-SeC were calculated. Rate ratios for class 7 against class 1 were calculated, as were the values of the (modified) relative index of inequality, ${ }^{20}$ both for men and for women.

\section{RESULTS}

Table 2 shows a pronounced gradient in age standardised rates of "not good" health for people in different social positions, increasing with worsening employment conditions.

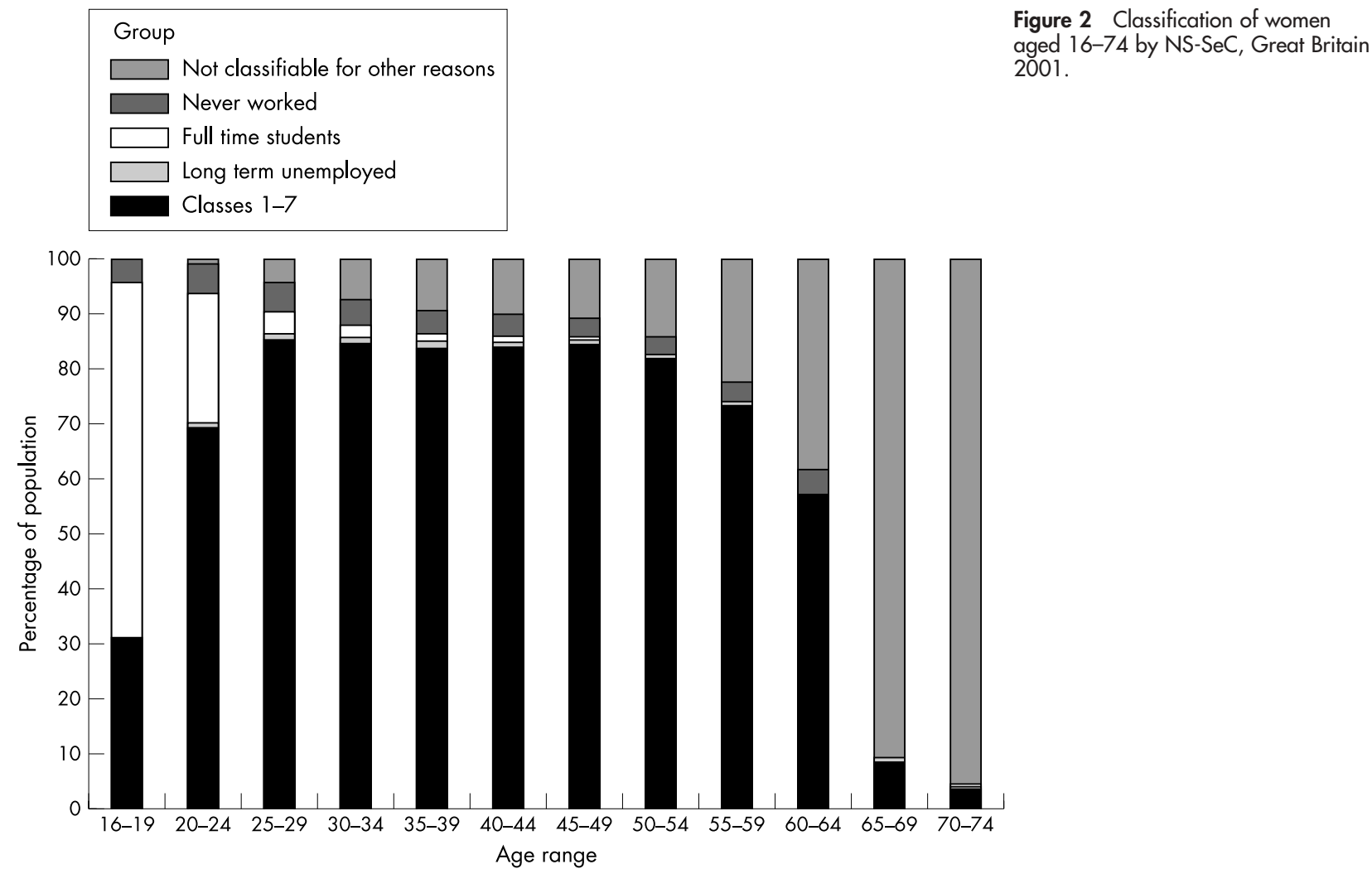




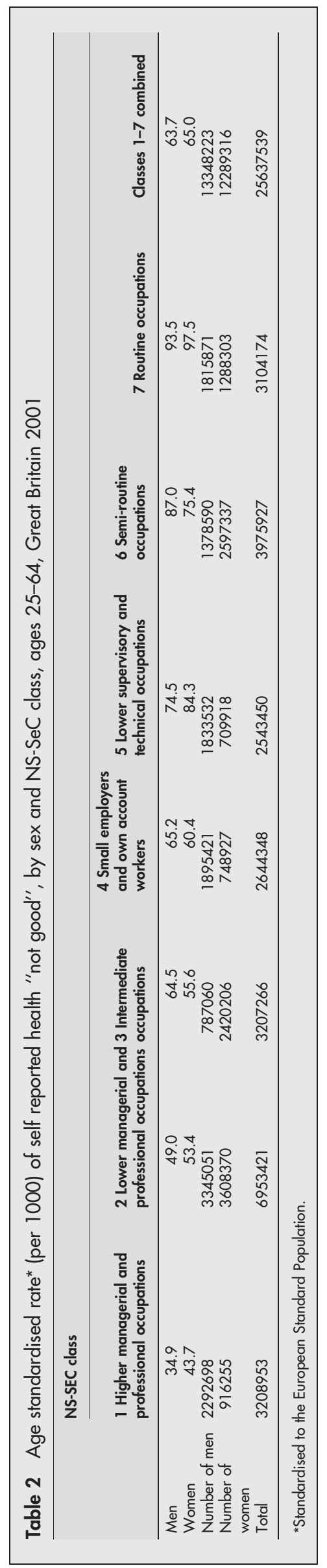

The rate for people in class 7 (routine occupations) was more than double that of people in class 1 (higher managerial and professional occupations)—95 per 1000 and 37 per 1000 respectively.

Health inequalities, in terms of "not good" health, were slightly larger for men than for women when measured by the NS-SeC, though the differences across the social scale for women were still substantial. The rate ratio of class 7 to class 1 was 2.7 for men and 2.2 for women (table 3 ).

Age standardisation adjusts for the different age structures of the classes within the NS-SeC, but does not fully take into consideration the very different population sizes. A fairly straightforward, and powerful, way of doing this is to use the (modified) relative index of inequality (RII). ${ }^{20}$ Figures 3 and 4 show the relation between the age standardised rates and the cumulative population share of the classes from class 7 through to class 1. Figure 3 shows that there is a clear linear relation between the age standardised rate of ill health and the cumulative population share for men (correlation coefficient $0.994, \mathrm{p}<0.005$ ). The RII is 2.98 for men aged 25 to 64 (table 3 ). Figure 4 shows that the linear relation is less pronounced for women (correlation coefficient 0.906, $p=0.056$ ). The RII is 2.25 for women aged 25 to 64 .

There were notable gender differences in general self rated health within each class. Although women had slightly higher rates of "not good" health in classes 1 to 7 combined, women in classes 3 (intermediate occupations), 4 (small employers and own account workers) and 6 (semi-routine occupations) had considerably lower rates than their male counterparts in the same class. The greatest proportional gender difference was within class 1 (higher managerial and professional occupations) where rates for women were $25 \%$ higher than for men in the same class.

In general, age specific rates of "not good" self rated health increased with both age and NS-SeC class (figs 5 and 6). The relations were particularly strong for men. Exceptions to the general trend should be noted, for example men in class 3 (intermediate occupations) had higher rates than men in class 4 (small employers) for ages 35 to 54; and men aged 60 to 64 in class 5 (lower supervisory and technical occupations) had higher rates than those in class 6 (semi-routine occupations).

For women, the age specific rates of "not good" health showed an increase with age up to 55-59 years old, but then declined slightly for women aged 60 to 64 in every social class except 4 (small employers). The patterns across the socioeconomic classification for women were also not as consistent as for men. Women aged 50 to 64 in class 2 (lower managerial and professional occupations) had higher rates than those in class 3 (intermediate occupations). The greatest deviation from an upward gradient was for women in class 5 (lower supervisory and technical occupations) who had considerably higher rates of "not good" health than those in class 6 (semi-routine occupations) across each age range with the exception of those aged 25 to 34 .

\section{DISCUSSION}

Self rated general health, included for the first time on the 2001 census, follows closely the social contours of the population as measured by the new government socioeconomic classification. Although not designed to be hierarchical, ${ }^{9}$ the NS-SeC does, in practice, reveal a pronounced gradient in self reported general health across the population of working age in Great Britain. As employment relations and conditions within the work environment become less favourable, so too does self rated health, for both men and women. At the extremes, these measures identify greater than twofold differences in "not good" health between people in the most and the least favourable employment 
Table 3 Comparison of age standardised rates of not good health, Great Britain 2001

\begin{tabular}{lllll}
\hline & $\begin{array}{l}\text { 1 Higher managerial } \\
\text { and professional } \\
\text { occupations }\end{array}$ & $\begin{array}{l}\mathbf{7} \text { Routine } \\
\text { occupations }\end{array}$ & $\begin{array}{l}\text { Rate ratio } \\
\text { (class 7: class 1) }\end{array}$ & $\begin{array}{l}\text { (Modified) relative } \\
\text { index of inequality }\end{array}$ \\
\hline Men, aged 25 to 64 & 34.9 & 93.5 & 2.68 & 2.98 \\
Women, aged 25 to 64 & 43.7 & 97.5 & 2.23 & 2.25 \\
\hline
\end{tabular}

conditions. More sophisticated tools, which take into consideration the relative sizes of the classes, still show this strong pattern.

Deviations from the general patterns exist and raise some interesting questions. Why do women aged 60 to 64 appear to have better self rated health than those aged 55 to 59? There is an obvious connection with the standard retirement age of 60 for women in Great Britain, but it is too simplistic to suggest that perceived health improves upon retirement. Even though those aged 60 to 64 who were retired and had a job in the past two years were classified, it should be noted that $38 \%$ of women aged 60 to 64 were not classified under the NS-SeC, compared with $23 \%$ of those aged 55 to 59 (fig 2). There is therefore potential for bias, in that women who continued to work after 60 , and were classifiable, may have had better health than those who retired and were not classifiable.

Another notable finding was the relatively poor health reported by women in class 5 (lower supervisory and technical occupations). Many more men than women are in this class, and this may have been a factor. However, the other male dominated classes ( 1 and 4) did not deviate from the general pattern in the same way, and men aged 55 to 64 in class 5 also had relatively poor health. This suggests that some other aspect of class 5 occupations is associated with poor health among both women and older men.

The way the census implemented the NS-SeC rules for allocating people to classes for data relating to Great Britain is clearly better at classifying men than women. Twice the proportion of women aged 25 to 64 were unclassified compared with men of these ages, $13.7 \%$ and $6.3 \%$ respectively. In each age group shown in figures 1 and 2, a higher proportion of women than men could not be classified. The rules implemented within the coding of the data for the 2001 census may account for this difference. Those who had worked at some point, were not long term

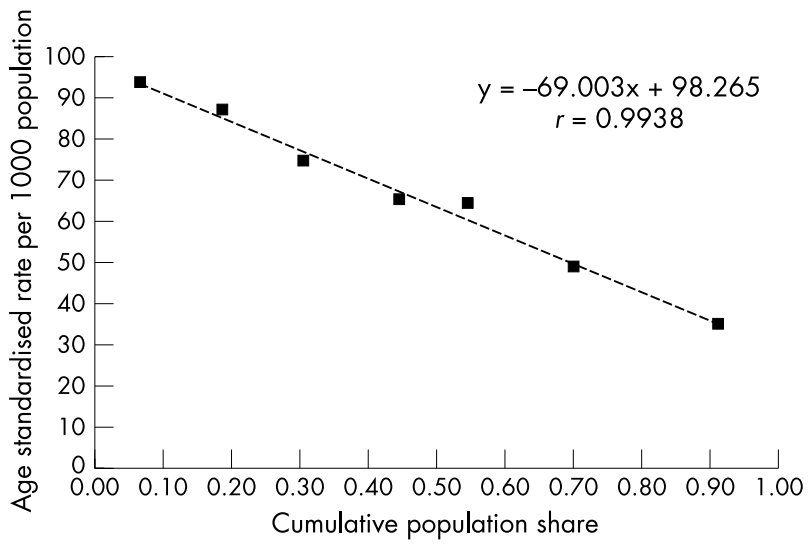

Figure 3 Age standardised rates of "not good" self reported health, men aged 25 to 64 , Great Britain 2001, by cumulative population share. unemployed, but last worked before 1996 (that is, over five years previous to the census date), were not allocated to a class. ${ }^{21}$ Nevertheless, an acceptable level of classification was still achieved for women, and this served to identify a substantial gradient in self rated general health in women. The size and direction of the gender gap varied by socioeconomic position. In some classes, the direction was of higher morbidity in women than in men. For other classes the pattern was reversed.

A major strength of this study is that it encompasses the whole population aged 25-64: 30.3 million people in Great Britain in total. This permits highly robust age adjusted estimates of the rates of self rated general health in different socioeconomic groups to be calculated and analysed. It also allows us to compare and contrast these health inequalities among women in different circumstances, unlike most studies that examine these only for men.

There are several limitations of this analysis. Data for Northern Ireland, which would have given a UK picture, could not be included because of incompatibility. The census questions related to the NS-SeC were coded in the countries of Great Britain in such a way that the vast majority of people over 65 could not be classified to an NS-SeC category. In contrast in Northern Ireland, the restrictions over length of time not in work for those under 65, and actually having to be in work for those over 65 , were not enforced. This meant that everyone in Northern Ireland enumerated in the 2001 census was allocated to a class. The specific restrictions on classifying those over 65 into NS-SeC classes makes it difficult, yet again, to study health inequalities among older people in the population. Despite restricting the study to 25 to 64 year olds, over $10 \%$ of people remained unclassifiable. As previously noted, this was a particular problem for women aged 60 to 64 . The relatively large age bands, and their lack of consistent length, supplied in the standard census tables also restricted the precision of the age standardisation. The overall patterns are probably not affected by this.

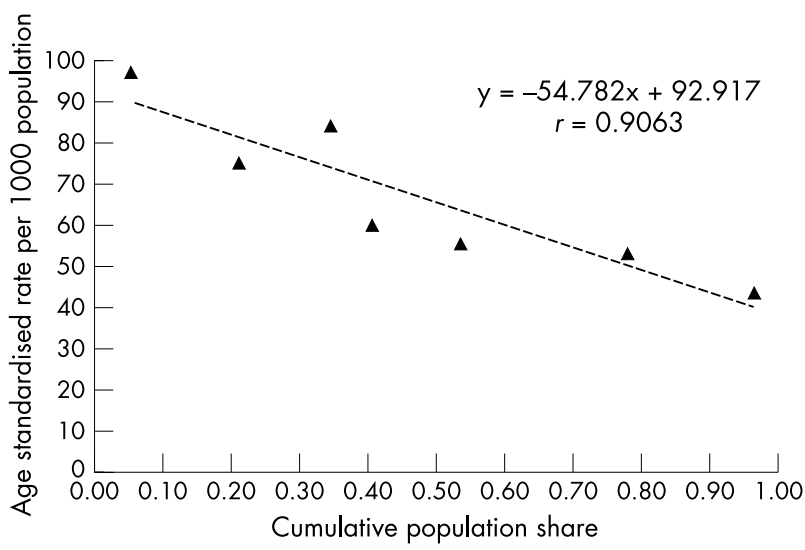

Figure 4 Age standardised rates of "not good" self reported health, women aged 25 to 64 , Great Britain 2001, by cumulative population share. 


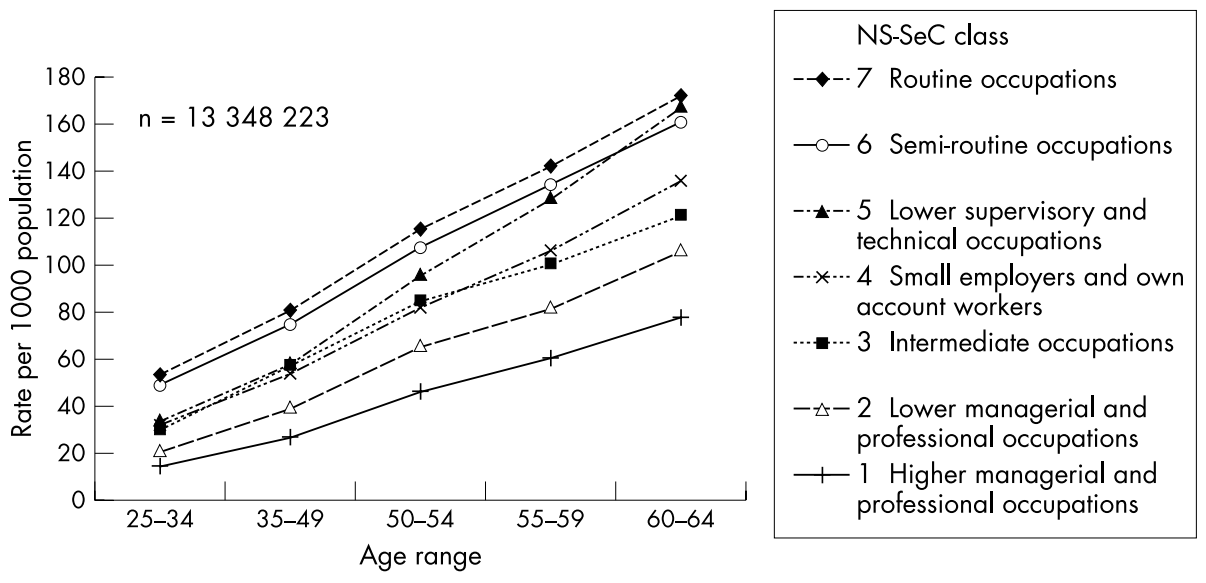

Figure 5 Age specific rates of "not good" self reported health, men aged 25 to 64 , Great Britain 2001, by age range and NS-SeC class.

The interim NS-SeC has been used by Sacker and colleagues to compare inequalities in mortality among men and women in a $1 \%$ sample of the 1981 census population, followed up to $1996 .{ }^{4}$ They found that the categorisation, based on employment relations, showed a powerful relation with mortality in men, but for women the gradient was both uneven and comparatively shallow. Their conclusion was that NS-SeC was a useful measure of inequality for men, but not so useful for women. Instead, they favoured one based on general social and material advantage of the household. This contrasts in part with our findings. Although the coding rules for the 2001 census implementation of the Ns-SeC were clearly better for men than women, the NS-SeC classification also functioned well for women, both in terms of the proportion able to be classified and the exploration of social inequality in health. These contrasting findings may in part be attributable to differences in interpretation of the classification during re-coding of the 1981 and coding of the 2001 census data for women, leading to differences in the proportion classified in each population group and their composition.

The contrasting findings also raise the possibility that self rated health may not be as powerful a predictor of mortality for women as for men, and may vary by socioeconomic grouping. To our knowledge, Burström and colleagues carried out the only study that tested the possibility of the differential predictive power of self rated health for men and women from different socioeconomic groups on Swedish linked survey and mortality data. ${ }^{16}$ They found self rated health to be a powerful predictor of mortality in Sweden, with only marginal differences in the predictive power by gender and socioeconomic group. In future years, this question needs to be addressed for the UK population, by using the self rated health question in the 2001 census and tracking subsequent mortality by gender and socioeconomic grouping in the ONS longitudinal study.

\section{CONCLUSIONS}

The 2001 census provides an important opportunity to study social inequalities in health, making use of the new government socioeconomic classification and the inclusion of self rated general health for the first time in an entire population census. The NS-SeC reveals a pronounced gradient in self rated health across the population of working age in Great Britain in 2001. At the extremes, these measures identify greater than twofold differences in poor health between people in the most and least favourable employment conditions. Although the census implementation of the NS$\mathrm{SeC}$ is better at classifying men than women, we found that it was still a useful measure when studying social inequality in health among women. The size of the gender gap in poor health varied by class. The greatest difference was among people in managerial and professional occupations, where rates of poor health for women were over $25 \%$ higher than for their male counterparts.

While the 2001 census data have great potential for further studies using this new socioeconomic measure, particularly in longitudinal follow up, we would not recommend using these NS-SeC data for studying inequalities among older or

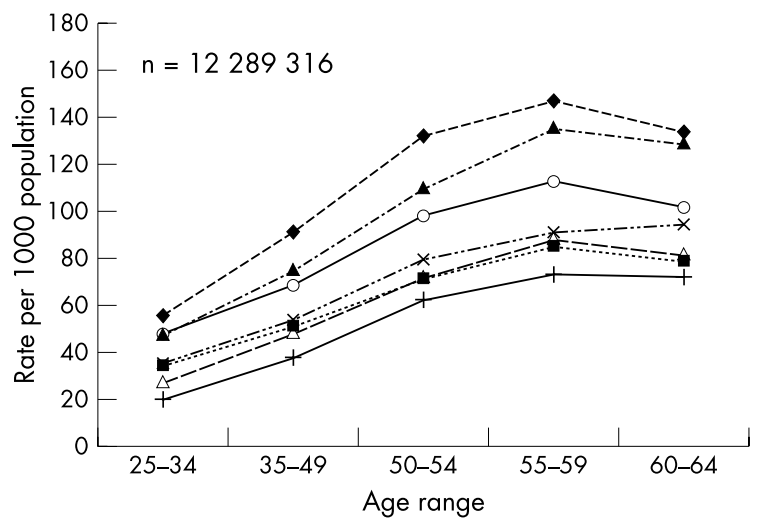

\section{NS-SeC class}

$\rightarrow-7$ Routine occupations

$\multimap-6$ Semi-routine occupations

-..-5 5 Lower supervisory and technical occupations

$-\cdots * \cdots 4$ Small employers and own account workers

- - 3 Intermediate occupations

$-\triangleleft-2$ Lower managerial and professional occupations

+1 Higher managerial and professional occupations
Figure 6 Age specific rates of "not good" self reported health, women aged 25 to 64 , Great Britain 2001, by age range and $\mathrm{NS}-\mathrm{SeC}$ class. 


\section{Key points}

- The 2001 census was the first to include a question on general health and to use the new government social classification (NS-SeC). It therefore provides the first opportunity to study inequalities in self rated health with the new classification, with the most complete possible coverage of people in the country.

- Although the new classification is biased towards men, as more men than women were classified, it still provides a useful measure for women.

- The census data show a pronounced gradient in self reported general health for both men and women across the social spectrum using the NS-SeC.

- The nature and size of the gender differences varies by class: professional and managerial women have the greatest health disadvantage, with a rate of poor health $25 \%$ higher than for men in the same class.

younger age groups, because of the large proportions of these age ranges that could not be classified in the scheme.

\section{CONTRIBUTORS}

FD, TD, and MMW conceived the idea for the analyses. FD and TD performed the analyses. All three authors contributed to the interpretation of the data, drafted and revised the paper, and approved the final version. FD and TD act as a guarantors.

\section{Authors' affiliations}

F Drever, T Doran, M Whitehead, Department of Public Health, University of Liverpool, Liverpool, UK

Funding: none.

Competing interests: none declared.

\section{REFERENCES}

1 Popay J, Bartley M, Owen C. Gender inequalities in health: social position, affective disorders and minor physical morbidity. Soc Sci Med 1992;36:21-32.

2 Bartley M, Popay J, Plewis I. Domestic conditions, paid employment and women's experience of ill-health. Sociology of Health and Illness 1992; 14:313-43.

3 Arber S. Comparing inequalities in women's and men's health: Britain in the 1990s. Soc Sci Med 1997;44:773-87.

4 Sacker A, Firth D, Fitzpatrick R, et al. Comparing health inequality in men and women: prospective study of mortality 1986-96. BMJ 2000;320:1303-7.

5 Arber S, Khlat M. Introduction to 'social and economic patterning of women's health in a changing world.' Soc Sci Med 2002;54:643-7.

6 In: Drever F, Whitehead M, eds. Health inequalities: decennial supplement. DS Series no 15. London: The Stationery Office, 1997.

7 Vågerö D. Health inequalities in women and men. BMJ 2000;320:1286-7.

8 Rose D. The registrar general's class schema: characteristics and criticisms. A report to ESRC. Colchester: ESRC Research Centre on Microsocial Change, University of Essex, 1994.

9 Rose D, O'Reilly K. The ESRC review of government social classifications. Swindon: ESRC/ONS, 1998.

10 Office for National Statistics. Standard occupational classification 2000 Volume 1: Structure and description of unit groups; Volume 2: The coding index. London: The Stationery Office, 2000.

11 Office for National Statistics. The national statistics socio-economic classification user manual. April 2002. (http://www.statistics.gov.uk/ methods quality/ns sec).

12 Rose D, O'Reily K. Constructing classes. Swindon: ESRC/ONS, 1997.

13 Fitzpatrick J, Dollamore G. Examining adult mortality rates using the National Statistics Socio-economic Classification. Health Statistics Quarterly 1999; summer: 33-40

14 Chandola T, Bartley M, Wiggins R, et al. Social inequalities in health by individual and household measures of social position in a cohort of healthy people. J Epidemiol Community Health 2003;57:56-62.

15 Idler E, Benyamini Y. Self-rated health and mortality: a review of twenty-seven community studies. J Health Soc Behaviour 1997;38:21-37.

16 Burström B, Fredlund P. Self-rated health: is it a good predictor of subsequent mortality among adults in lower as in higher social classes? J Epidemiol Community Health 2001;55:836-40.

17 Office for National Statistics. Census 2001: CD supplement to the national report for England and Wales and Key Statistics for local authorities in England and Wales [on CD-ROM]. London: ONS, 2003.

18 General Register Office of Scotland. http://www.gro-scotland.gov.uk/ grosweb/grosweb.nsf/file7/\$file/stan015-128.xls

19 Armitage P, Colton T. Encyclopedia of biostatistics. Chichester: Wiley, 1998.

20 Mackenbach JP, Kunst AE. Measuring the magnitude of socio-economic inequalities in health: an overview of available measures illustrated with two examples from Europe. Soc Sci Med 1997;44:757-71.

21 National Office for Statistics. http://www.statistics.gov.uk/census2001/ pdfs/glossary.pdf 